Acta Universitatis Wratislaviensis No 4053

Studia Linguistica XL Wrocław 2021

https://doi.org/10.19195/0137-1169.40.8

ANNETTE SIEMES

ORCID: 0000-0001-6129-0900

Uniwersytet Wrocławski, Polen

\title{
Gesundheit/zdrowie und Krankheit/choroba als kommunikativ semantisierte sprachliche Größen und Elemente des Systems der Kollektivsymbolik in Deutschland und Polen
}

Der folgende Artikel betrachtet die Wörter Gesundheit und Krankheit sowie ihre polnischen Pendants zdrowie und choroba als kommunikativ semantisierte Elemente, die in beiden Sprachen als Kommunikationskonzepte funktionieren und eine kollektivsymbolische Funktion übernehmen bzw. an der Entstehung und Konsolidierung des Systems der Kollektivsymbolik, wie es von Michael Fleischer seit 1993 für beide Länder ${ }^{1}$ mehrfach untersucht wurde, beteiligt sind (vgl. Fleischer 1995, 1996, 2003). Im Rahmen der im vorliegenden Text eingenommenen Perspektive interessiert uns vorrangig, wie die vier hier analysierten Wörter axiologisch eingeschätzt werden und wie sich ihre Bedeutung aus einer pragmatischen sowie kommunikationsanalytischen Sicht gestaltet - dann, wenn Kommunikationsteilnehmer um deren Charakterisierung gebeten werden. Eben dies fand im Rahmen einer Untersuchung der Wörter Gesundheit/zdrowie und Krankheit/choroba (unter zahlreichen weiteren) in ihrer potentiellen Funktion als Kollektivsymbole statt; der vorliegende Text basiert somit auf auszugsweisen, hier jedoch in gesonderter Perspektive betrachteten Daten, die aus einer umfassenden, langfristig angelegten Studie zu Kollektivsymbolen hervorgegangenen sind, deren aktuelle Edition im Rahmen eines von der Deutsch-Polnischen Wissenschaftsstiftung geförderten Projekts realisiert wurde (vgl. Fleischer/Siemes/Grech 2021). Ein spezielles aktuelles Interesse an den für die vorliegende Betrachtung gewählten Wörtern $G e-$ sundheit/zdrowie und Krankheit/choroba ergibt sich aus der Corona-Thematik,

1 Sowie im Jahr 1997 zusätzlich für Russland. 
vor deren Hintergrund die Frage nach ihrer Rolle und Bedeutung im System der Kollektivsymbolik besonders zentral erscheint.

\section{Grundlagen}

Die Untersuchung von Kollektivsymbolen als spezifischen Elementen, welchen über ihre sprachliche Manifestation und lexikalische Bedeutungen hinaus eine besondere Funktion in der Kommunikation zukommt und welche auf besondere Weise mit breiteren, kommunikativen Bedeutungen versehen werden, wurde in ihrer konkreten Form durch Michael Fleischer erarbeitet und empirisch umgesetzt sowie in der Allgemeinen Kommunikationstheorie theoretisch fundiert (Fleischer 2006 sowie 2007). Sie lässt sich - allgemein und in einem breiten Verständnis der entsprechenden Bereiche - anschließen an Forschungen zu Werten und Weltbild sowie Schlüssel- und Fahnenwörtern/słowa sztandarowe (vgl. Bartmiński, Pisarek, Wierzbicka); der Begriff der Kollektivsymbole selbst entstammt Jürgen Links diskursanalytischen Arbeiten, wurde dort ehemals jedoch anders konzeptualisiert (s. Link 1982, 1999).

Vor diesem Hintergrund ist es einerseits unerlässlich, einführend einige Grundlagen zu referieren; zugleich soll jedoch darauf hingewiesen werden, dass es dabei lediglich um eine kurze Einordnung der hier vorgestellten Ergebnisse geht und nur gehen kann, welche im Rahmen eines Artikels gezwungermaßen recht oberflächlich bleiben muss. Für die im Weiteren vorgenommene Betrachtung ist sie jedoch insofern von Belang, als die hier besprochenen Ergebnisse, ungeachtet ihrer Aktualität angesichts der Corona-Pandemie, nicht einer ad hoc durchgeführten Einzelstudie entstammen, sondern das Resultat eines komplexen Forschungsprojekts bilden, in das sowohl die Planung und der Prozess der Datenerhebung als auch die Analyse des gewonnenen Materials theoretisch und methodologisch eingebettet sind.

Es kann also davon ausgegangen werden, dass den hier vorgestellten Wörtern derzeit eine besondere Rolle zukommt, da sie Bereiche betreffen, deren Relevanz nicht nur in phraseologisierten, weitgehend zeitunabhängigen bzw. in der Zeit stabilen Kontexten manifest wird (z.B. - wenn es um die positive Ausformung, also Gesundheit, geht - bei guten Wünschen zu allen möglichen Gelegenheiten etc.), sondern aktuell auf eine nie dagewesene Weise in den Vordergrund des Alltagslebens und insbesondere medial vermittelter Kommunikationen - kurz: des Interdiskurses - getreten sind. ${ }^{2}$ So erscheint derzeit die Frage durchaus von besonderem Interesse, wie sich die kommunikative Verhandlung der Bedeutung dieser Wörter sowohl im Hinblick auf deren Semantik als auch in der axiologischen Dimension -

2 Ähnliches gilt mutmaßlich für das Wort Sicherheit, das jedoch nur in Deutschland in - ohnehin starker - kollektivsymbolischer Funktion auftritt und dort (aufgrund der Ergebnisse des ersten Erhebungsschritts) weiter untersucht wurde. 
das heißt im Hinblick auf den Stellenwert der durch sie bezeichneten Themen im Interdiskurs - im Einzelnen gestaltet. Die aktuelle Situation bietet dabei jedoch lediglich den Anlass; das Forschungsinteresse ist auf die allgemeinen Tendenzen im Hinblick auf die mögliche kollektivsymbolische Funktionalisierung der Wörter gerichtet, die hier anhand der Semantik und der Bewertungsdimension sowie im Hinblick auf die Frage der kommunikativen Bedeutung beobachtet wurden. Die hier besprochenen Daten wurden, passend dazu, kurz vor bzw. noch zu Beginn der Pandemie, diverser Lockdowns usw. im März 2020 erhoben und haben somit den Vorteil, einerseits eine Momentaufnahme darzustellen, zugleich aber auch Rückschlüsse auf längerfristig konstituierte Bedeutungs- und Bewertungskonstellationen im Netz der Kollektivsymbole zuzulassen, zumal die Wörter Gesundheit und Krankheit in Deutschland bereits in der ersten Erhebung im Jahr 1993/94 untersucht worden sind (vgl. Fleischer 1996).

Eine solche langfristig bzw. auf das Erkennen längerfristig wirksamer Konstellationen im Netz der Kollektivsymbole angelegte Betrachtung erscheint sinnvoll aufgrund der (potentiellen) Eigenschaft der hier analysierten Wörter als Kollektivsymbole (oder als Elemente, die deren System katalysatorisch stützen), deren theoretischer Hintergrund hier nun kurz referiert werden soll.

\section{Die Stratifikation der Kommunikation und die Rolle der Kollektivsymbole}

In kommunikationswissenschaftlicher Sicht lässt sich zunächst die Stratifikation von Kommunikation in die Bereiche von Quasi-Diskursen, Diskursen sowie des Interdiskurses heranziehen, ${ }^{3}$ um den Wirkungsbereich von Kollektivsymbolen, also die Ebene des Interdiskurses, einzugrenzen.

1. Quasi-Diskurse entstehen in sozialen Gruppen (Freundeskreisen, Cliquen, Gruppen von Studierenden, an einem konkreten Arbeitsplatz, in der Familie etc.). Sie weisen den vergleichsweise höchsten Freiheitsgrad bezüglich der in ihrem Rahmen vorgenommenen Bedeutungszuschreibungen auf - neue Elemente und Konstellationen können schnell eingeführt und weitgehend modifiziert werden (im Vergleich zu dem, was von anderen diskurshaften Konstellationen her vorgesehen ist), aber ebenso schnell wieder verschwinden.

2. Diskurse, die in Supragruppen (in der Theorie auch als Subkulturen bezeichnet - z.B. vor dem Hintergrund einer bestimmten Berufsgruppe, Branche, Subkultur) ausgebildet werden, zeichnen sich hingegen durch eine größere Stabilität aus und besitzen eine solidere, verbindlichere Basis, die durch die jeweils hinter ihnen stehenden und sie generierenden sozialen Formationen geschaffen und

${ }^{3}$ Für eine detaillierte Besprechung im gesamttheoretischen Kontext siehe Fleischer 2006:295-303, 2007:249-254. 
stabilisiert wird. Ein Diskurs ist in der hier zugrundeliegenden Herangehensweise somit das systemische Repertoire von Bedeutungen (Interpretanten im Sinne von Peirce) sowie generativer und anwendungsbezogener Regeln und Normen, welches die Kommunikationen der jeweiligen sozialen Formation organisiert und über deren kommunikative und soziale Spezifik entscheidet. Der Diskurs ist somit als kommunikativ bedingte Art und Weise zu sehen, wie und mit Hilfe welcher Interpretanten $(\approx$ Bedeutungszuschreibungen) die jeweilige Supragruppe in Kommunikationen erscheint, wodurch sie zugleich im Gesellschaftssystem ihre Kohärenz sichert. Der (jeweilige) Diskurs kreiert so die kommunikative Wirklichkeit einer gegebenen Formation und sichert ihre Diskretheit, also Unterscheidbarkeit vor dem gesellschaftlichen Hintergrund (zur empirischen Untersuchung dieser Diskursebene vgl. Fleischer/Siemes 2020).

3. Die Gesellschaft und ihr Interdiskurs indes sind der für die hier untersuchten Größen (Kollektivsymbole) wesentliche Bereich, in dem die dritte, kommunikative Wirklichkeit ${ }^{4}$ verhandelt bzw. als gemeinschaftlich wirksame Grundlage und potentieller Bezugsrahmen für jegliche geäußerten und in gesellschaftliche Wirklichkeit eingebrachten Kommunikationen produziert wird. Hierbei bilden Kollektivsymbole ein wesentliches Element - ihre relative Stabilität (die sich, wie oben erwähnt, empirisch beobachten lässt) stellt einerseits einen Garanten für das Funktionieren gesellschaftlich-kommunikativer Zusammenhänge dar (sozusagen, weil wir uns bei ihnen besonders darauf verlassen können, dass sie einen vorbereiteten Bedeutungs- und Interpretationsrahmen bieten); andererseits ermöglichen sie es, Aktualitäten und unvorhersehbare Ereignisse an die jeweils passenden Anknüpfungspunkte im bestehenden kollektivsymbolischen Netz anzuschließen (was im Hinblick auf die Pandemie und die Themen Gesundheit/Krankheit gegenwärtig geschieht).

Kollektivsymbole zählen somit, neben einigen wenigen anderen, zu den wesentlichsten Diskurselementen, und zeichnen sich gegenüber anderen Elementen der Sprache dadurch aus, dass sie im Rahmen einer interdiskurshaften Semantisierung mit einer über die lexikalische Bedeutung, die vereinfachend gesagt, so und nicht anders kodiert im Sprachsystem als allgemein-sprachliche Bedeutung gilt, hinausgehenden kommunikativen Bedeutung versehen werden, welche ihre Anwendbarkeit erweitert und zugleich vor dem gesellschaftlichen Hintergrund reguliert. Aufgrund ihrer deutlich positiven oder negativen Wertung ermöglichen sie es darüber hinaus, schnell und sozusagen unter Garantie von Anschlussfähigkeit (Luhmann) an bestehende Bereiche von Konsens oder auch Dissens anzuknüpfen und sich im Hinblick auf dieselben zu positionieren (und bilden damit ein Element von Normalisierungsprozeduren in Kommunikation ${ }^{5}$ ).

${ }^{4}$ Fleischer 2006, vgl. vorhergehende Fußnote.

5 Mehr zum Thema Normalität und Normalisierungsprozeduren in Kommunikation - vgl. Siemes 2014, 2015; im Hinblick auf empirische Einzeluntersuchungen ausgewählter Kollektivsymbole in 
Kollektivsymbole sind Zeichen, die einen derart und dermaßen ausgeprägten Interpretanten [im Peirce'schen Sinne - A.S.] besitzen, daß sie eine vom gegebenen Interdiskurs bedingte kommunikative Bedeutung und eine stark ausgeprägte positive oder negative und damit differenzierende Färbung (Wertung) aufweisen, die für die gesamte Gesellschaft gelten und bei denen der Interpret auf besondere Kenntnisse bezüglich des Bedeutungs- und hauptsächlich des Zeichen-Interpretanten angewiesen ist. Diese besonderen Kenntnisse werden im gesellschaftlichen Sozialisationsprozeß wie auch während der laufenden Kommunikationen im Rahmen einer Gesellschaft erworben und erlauben damit dem Interpreten das adäquate Kommunizieren im Rahmen seines Interdiskurses. Dabei weicht die kommunikative Bedeutung von der allgemeinsprachlichen (lexikalischen) in den meisten Fällen stark ab. Kollektivsymbole sind die wichtigsten Elemente des Interdiskurses (Fleischer 2006:301, Hervorhebungen im Original; vgl. auch ders. 2007:254).

Die Möglichkeit der positiven oder negativen Ausprägung unterscheidet Kollektivsymbole zugleich von Werten, zumindest in deren umgangssprachlicher, positiv ausgerichteter Version. Als sozusagen klassische Beispiele, für die über lange Zeiträume kollektivsymbolische Eigenschaften bzw. eine entsprechende Funktionalisierung in der Kommunikation nachgewiesen werden können, lassen sich Krieg/ wojna, Frieden/pokój oder auch Familie/rodzina nennen. Diese Beispiele, die weitgehend unabhängig von ihrer jeweiligen konkreten (kommunikations-)semantischen Ausprägung im jeweiligen Gesellschaftssystem kollektivsymbolisch funktionalisiert sind (was in unserem Fall für Deutschland als auch Polen über einen Zeitraum von rund 25 Jahren empirisch untersucht werden konnte), sollten jedoch nicht darüber hinwegtäuschen, dass eine der wesentlichen Eigenschaften von Kollektivsymbolen ihre distinktive Kraft ist, auf welche im zweiten Teil der Defintion hingewiesen wird und die die Kollektivsymbole, über deren Relevanz als Untersuchungsgröße in sprach- und kommunikationswissenschaftlichen Studien, zusätzlich für interkulturelle Betrachtungen besonders interessant macht.

Im Fall der Kollektivsymbole dominieren kulturelle (diskursive) Bedeutungen über die lexikalischen (sind relevanter als die lexikalischen Bedeutungen). Die Kollektivsymbole basieren auf allgemeinen Eigenschaften der natürlichen Sprache, was bedeutet, dass die sie repräsentierenden Wörter eine lexikalische Bedeutung besitzen, die der jeweiligen Sprache zu eigen ist. Sie besitzen jedoch ebenso einen kulturell bedingten, zur gegebenen Einzel-Kultur gehören-

Polen (rodzina/Familie, dom/Haus, zdrowie/Gesundheit) - 2013, 2016, 2016a. Der in diesen Arbeiten für die Anwendung auf kommunikationswissenschaftliche Fragestellungen entwickelte Forschungsansatz geht zurück auf Jürgen Links Konzept des Normalismus (Link 1992, 1996, 2013; Link/Loer/ Neuendorff 2003). 
den Bedeutungsüberschuss, der den in verschiedenen Kulturen unterschiedlich gegebenen Systemzustand widerspiegelt (Habrajska 2012:48). ${ }^{6}$

Im Zuge der empirischen Untersuchung von Kollektivsymbolen wird vor dem Hintergrund der oben skizzierten theoretischen Beschreibung desweiteren relevant, dass manchen Wörtern zwar zum jeweils aktuellen Zeitpunkt aufgrund der Datenlage kein kollektivsymbolischer Status zugeschrieben werden kann (beispielsweise weil kommunikative Bedeutungen nicht deutlich genug ausgeprägt sind), diese aber als sogenannte Katalysatoren einzustufen sind (vgl. Fleischer/Siemes/Grech 2021, Kap. 1.7.), da andere ermittelte Aspekte dafür sprechen, dass ihnen dennoch eine besondere Rolle zukommt. ${ }^{7}$ Sie stützen das System der Kollektivsymbole und sind wesentlich daran beteiligt, seine jeweilige Ausprägung zu modellieren, u.a. indem sie zur Charakterisierung der Bedeutung anderer Symbole herangezogen werden und letztere (über ihren Einfluss auf die Semantik der jeweils durch sie mitdefinierten Wörter hinaus) auf spezifische Weise miteinander verbinden und also die Ausformung des gesamten Netzes mit bedingen.

\section{Die Bewertung der Wörter Gesundheit/zdrowie und Krankheit/choroba}

Für eine grundsätzlich, zeit- bzw. aktualitätsunabhängig gegebene wichtige Rolle der hier vorgestellten Wörter Gesundheit und Krankheit sowie zdrowie und choroba spricht zunächst, dass diese in einem ersten Untersuchungsschritt zur Kollektivsymbolik auf eine diesbezügliche offene Frage ${ }^{8}$ hin mehrfach als wichtige Wörter genannt werden und auf der so ermittelten Liste häufiger Nennungen im oberen Bereich erscheinen. ${ }^{9}$ Beide kommunikativen Größen und Themenbereiche haben somit ausreichende Strahlkraft, um bei einer ungestützten Erhebungsweise,

${ }^{6}$ Übersetzung - A.S. Originalversion: „W przypadku symboli kolektywnych znaczenia kulturowe (dyskursowe) dominują nad leksykalnymi (są istotniejsze, niż znaczenia leksykalne). Symbole kolektywne bazują na ogólnych własnościach języka naturalnego, co oznacza, że reprezentujące je wyrazy posiadają znaczenie leksykalne, właściwe danemu językowi. Posiadają jednak również naddatek znaczeniowy, uwarunkowany kulturowo, przynależny do danej kultury jednostkowej i odmiennie w różnych kulturach obrazujący stan danego systemu“"(Habrajska 2012:48).

7 Z.B. ihre klar positive oder negative Bewertung sowie ihre Nennung als wichtige Wörter im Rahmen einer entsprechenden offenen Frage in einem ersten Untersuchungsschritt.

${ }^{8}$ Schreiben Sie bitte unten positiv und negativ markierte Worte oder Ausdrücke auf, die Ihrer Meinung nach für die Menschen in Deutschland wichtig sind. Geben Sie spontan möglichst viele Wörter oder Ausdrücke an, auch wenn Sie sich nicht ganz sicher sind. Polnische Version: Proszę napisać poniżej pozytywnie i negatywnie nacechowane słowa lub wyrażenia istotne Pana/Pani zdaniem dla ludzi w Polsce. Proszę podać spontanicznie możliwie dużo słów lub wyrażeń, nawet jeśli nie ma Pan/ Pani zupełnej pewności, czy są one istotne.

${ }^{9}$ Die Ergebnisse dieses ersten Untersuchungsschritts hier im Einzelnen vorzustellen und dessen Einbettung in die weitere Erhebung näher zu erläutern, würde den Rahmen eines Artikels definitiv 
ohne dass Wörter zur Auswahl vorgelegt worden wären, aktiv von den Versuchspersonen (im Folgenden - Vpn) wiederholt genannt zu werden. Sie werden also in der Kommunikation selbst dann als wichtig aktualisiert, wenn zugleich das maximal mögliche Gesamtrepertoire an weitgehend beliebigen anderen, als wichtig einstufbaren Wörtern zur Verfügung steht. ${ }^{10}$

Die Bewertung der Wörter, die schließlich in einem weiteren Untersuchungsschritt (unter anderen gewählten Begriffen) den Befragten vorgelegt wurden, zeigt dann klar für beide Sprach- und Gesellschaftssysteme eine (äußerst) hohe Relevanz bzw. eindeutig positive bzw. negative Einstufung der hier analysierten kommunikativen Größen. Diese zeigt sich somit unabhängig vom jeweiligen sonstigen gegebenen, gesellschaftlich-kulturell geprägten Hintergrund, aus dem sich wiederum Unterschiede im Hinblick auf die Semantik und kommunikativen Bedeutungen ergeben können.

Der Vollständigkeit halber und zur besseren Einordnung werden die entsprechenden Werte hier für alle aktuell untersuchten Wörter präsentiert; auf die restlichen Bewertungen kann jedoch im vorliegenden Artikel aus Platzgründen nicht näher eingegangen werden. Ersichtlich wird, dass beide Bewertungshierarchien (D/PL) sich weitgehend ähneln und stärkere Abweichungen nur einzelne Wörter betreffen. Eine nähere Besprechung wie auch die Herleitung der Auswahl der untersuchten Begriffe ist in der oben genannten Publikation (Fleischer/Siemes/Grech 2021) zu finden.

Tabelle 1. ${ }^{11}$ Die Hierarchie der Wörter im zweiten Schritt beider Umfragen (Deutschland/Polen 2020), Rangliste anhand des arithmetischen Mittels der Bewertungen durch je 1000 Vpn auf einer Skala von +100 (sehr positives Wort) bis -100 (sehr negatives Wort)

\begin{tabular}{|l|c|c|l|c|c|}
\hline \multicolumn{1}{|c|}{ Untersuchung } & $2020 \mathrm{D}$ & $2020 \mathrm{PL}$ & \multicolumn{1}{|c|}{ Untersuchung } & 2020D & 2020PL \\
\hline Wort & Bew. & Bew. & Wort & Bew. & Bew. \\
\hline Gesundheit / zdrowie & $\mathbf{9 1}$ & $\mathbf{9 0}$ & Glaube / wiara & - & 63 \\
\hline Frieden / pokój & 90 & 82 & Tradition / tradycja & 53 & 67 \\
\hline
\end{tabular}

sprengen - für eine umfassende Besprechung siehe Fleischer/Siemes/Grech 2021, Kap. 3.1.1. sowie 4.1.1.; für Details zum methodischen Vorgehen - Kap. 2.

10 Entsprechend breit sind die Ergebnisse dieser Untersuchungsetappe insgesamt gestreut, was zugleich bedeutet, dass ein Vorkommen von Wörtern im oberen Bereich der Häufigkeitsliste lediglich als erster - aber durchaus deutlicher - Hinweis auf eine besondere Rolle des jeweiligen Wortes gewertet werden kann. Entscheidend ist/war somit, welche Wörter überhaupt und wiederholt genannt werden und die so ermittelte Häufigkeitsliste anführen. Gesundheit zählt dabei (mit 107 Nennungen) zu den vier am häufigsten genannten positiven Wörtern, Krankheit (46 Nennungen) zu den fünf am häufigsten genannten negativen Wörtern (analog dazu in Polen zdrowie (28 Nennungen) zu den 30 am häufigsten genannten positiven Wörtern, choroba (37 Nennungen) zu den 10 am häufigsten genannten negativen Wörtern) - und dies jeweils ohne lexikalische Vereinheitlichungen, beispielsweise die Zusammenfassung mit adjektivischen Formen.

11 Quelle aller Tabellen: eigene Daten und Datenanalyse. 


\begin{tabular}{|l|c|c|l|c|c|}
\hline \multicolumn{1}{|c|}{ Untersuchung } & $2020 \mathrm{D}$ & 2020PL & \multicolumn{1}{|c|}{ Untersuchung } & 2020D & $2020 \mathrm{PL}$ \\
\hline Wort & Bew. & Bew. & Wort & Bew. & Bew. \\
\hline Freiheit / wolność & 88 & 86 & Arbeit / praca & 52 & 71 \\
\hline Liebe / miłość & 88 & 88 & Geld / pieniądze & 51 & - \\
\hline $\begin{array}{l}\text { Ehrlichkeit / [szczerość] / } \\
\text { uczciwośc }\end{array}$ & 85 & 84 & Nation / naród & 41 & 63 \\
\hline Freundschaft / przyjaźń & 85 & 83 & Vaterland / ojczyzna & 40 & 73 \\
\hline Haus / dom & - & 85 & Ausländer / obcokrajowcy & 9 & - \\
\hline Familie / rodzina & 84 & 88 & $\begin{array}{l}\text { Klimawandel / zmiana } \\
\text { klimatu }\end{array}$ & -31 & - \\
\hline das Gute / dobro & - & 81 & Wut/Zorn / złość & - & -52 \\
\hline $\begin{array}{l}\text { Sicherheit / } \\
\text { bezpieczeństwo }\end{array}$ & 81 & - & Krankheit / choroba & $-\mathbf{6 8}$ & $-\mathbf{5 2}$ \\
\hline Hilfe / pomoc & 75 & 79 & Dummheit / głupota & - & -55 \\
\hline Urlaub / urlop & 73 & - & Rüpelhaftigkeit / chamstwo & - & -65 \\
\hline Ehre / honor & - & 72 & $\begin{array}{l}\text { Arbeitslosigkeit / } \\
\text { bezrobocie }\end{array}$ & -69 & -47 \\
\hline Heimat / mała ojczyzna & 72 & - & Armut / bieda & -73 & -58 \\
\hline Kinder / dzieci & 67 & 78 & Hass / nienawiść & -76 & -68 \\
\hline $\begin{array}{l}\text { Umweltschutz / ochrona } \\
\text { środowiska }\end{array}$ & 67 & 66 & Terror & -86 & - \\
\hline Demokratie / demokracja & 64 & 43 & Krieg / wojna & -87 & -75 \\
\hline
\end{tabular}

Die einhellig hohe Bewertung (auf einer Skala von +100 (sehr positives Wort) bis -100 (sehr negatives Wort) gilt, wie in der Tabelle zu sehen, besonders für Gesundheit bzw. zdrowie, welche im positiven Bereich die Bewertungshierarchien in beiden Ländern sogar anführen - noch vor „klassischen“ kollektivsymbolisch funktionalisierten Wörtern wie Liebe oder Freiheit. Dabei ist zu beachten, dass dieses Bild, in dem Gesundheit sozusagen den Favoriten unter den bewerteten Begriffen stellt, sich noch ganz zu Beginn der pandemiebedingten Situation (im März 2020) ergab, als erste Maßnahmen zwar gerade ergriffen worden waren, jedoch das Andauern und das Ausmaß der einschneidenden Veränderungen und Schwierigkeiten noch in keiner Weise sichtbar waren und die Auswirkungen auf die Bewertung der Wörter somit als (möglicherweise - noch) eher gering einzuschätzen sind. Für eine langfristiger gültige, stabile (nicht nur durch Aktualitäten bedingte) hohe Wertung spricht auch, dass zumindest in Deutschland Gesundheit auch in der bereits 1994 erfolgten ersten Untersuchung (Fleischer 1996) mit an der Spitze der Bewertungen stand - damals an zweiter Stelle direkt hinter Frieden (für Polen wurden beide Wörter erst in der Erhebung aus 2020 zum Vergleich mit einbezogen). Da es hier um den axiologischen Stellenwert und die Beschreibung der Semantik 
vor dem Hintergrund der aktuellen, besonderen Situation gehen soll, werden die Ergebnisse aus den vorigen Untersuchungen jedoch hier nicht weiter besprochen sowie Unterschiede wie auch Ähnlichkeiten nicht im Einzelnen dargelegt. Allgemein lässt sich feststellen, dass die durchschnittlichen Bewertungen für viele Wörter (insbesondere im Hinblick auf stark im System verankerte Symbole wie Liebe, Freiheit, Familie oder auch Krieg) erstaunlich stabil bleiben und zuweilen identisch mit jenen sind, die vor rund 25 Jahren (sowie in Polen zusätzlich im Jahr 2000) ermittelt wurden (vgl. Fleischer 1995, 1996 sowie 2003).

\section{Die Bildung der semantischen Profile}

Der nächste Analyseschritt bezieht sich schließlich auf die durch die Vpn vorgenommene Charakterisierung der Wortbedeutungen - hier im Hinblick auf die vier Wörter, die vor dem aktuellen Hintergrund besonders interessant erscheinen. Dabei sind zumindest zwei verschiedene Perspektiven von Belang - die Häufigkeitslisten sowie die semantischen Profile -, um über die lexikalische Ebene hinaus, auf der bestimmte Nennungen sich wörtlich wiederholen, auch die kommunikative Bedeutung erfassen zu können. Letztere umfasst, wie oben skizziert, mehr bzw. potentiell anders und breiter geartete Dimensionen als jene, die aufgrund einer reinen Häufigkeitsliste sichtbar werden. In den semantischen Profilen wird deshalb eine zusätzliche Perspektive eingenommen. Diese erlaubt es, neben inhaltlichen Dimensionen, welche gleich oder ähnlich lautende Nennungen umfassen, auch solche Antwortgruppen aus dem Material herauszuarbeiten, für die bestimmte formale Kriterien bzw. Muster entscheidend sind - also jeweils die gleiche Art und Weise, über etwas zu sprechen, z.B. für Äußerungen herangezogene Konzepte oder Bezugsrahmen, welche dann - lexikalisch unterschiedliche - Antworten miteinander verbinden.

Im Weiteren werden daher zum einen Häufigkeitslisten präsentiert und zum anderen die wesentlich breiteren semantischen Profile. Die Listen der häufigsten Antworten geben uns Auskunft darüber, welche Nennungen sich durch wortgleiche Wiederholung besonders deutlich unter allen (darüber hinaus - breit gestreuten) Antworten hervorheben und also bereits auf der Ebene der Versprachlichung eigenständige Größen bilden. Die semantischen Profile wurden aufgrund des gesamten Antwortmaterials gebildet, um auch Bedeutungskomponenten zu erfassen, die auf einer reinen Häufigkeitsliste unter diversen anderen, seltener auftretenden Versprachlichungen untergehen würden. Gerade diese Komponenten sind aus kommunikationsanalytischer Sicht besonders interessant, weil sie Ähnlichkeiten aufweisen, die auf der kommunikativen Ebene zustande kommen, also gewissermaßen dort, wo es nicht alleine darum geht, was gesagt, sondern auch wie es gesagt wird.

So erlauben die Ergebnisse in der Gesamtschau dann nicht nur das zu erfassen, was im Hinblick auf eine gegebene kommunikative Bezugsgröße gesagt wird 
(welche Nennungen vorkommen), sondern auch Einblick dahingehend zu erhalten bzw. sichtbar zu machen, wie/auf welche Weise, mit welchen zusätzlichen Konzepten im Hintergrund auf die gegebene Sache Bezug genommen wird bzw. werden kann. Es geht somit nicht um eine reine, übliche Kategorisierung der Daten, sondern darum, durch diese Zusammenfassung der Daten eine Grundlage für die zusätzliche Analyse eines, theoriegeleitet erarbeiteten, speziellen Untersuchungsgegenstands (der Kollektivsymbolik) herzustellen.

Anzumerken ist, dass eine solche, breiter orientierte Art der Zusammenfassung von Textmaterial selbstverständlich immer auf verschiedene Weisen vorgenommen werden kann und hier keinesfalls als die einzig mögliche Version dargestellt werden soll. Zum einen sind generell weitere Perspektivierungen im Rahmen der Datenanalyse möglich, zum anderen können, je nach Forschungsinteresse, jeweils Zuordnungen und Dimensionsbildungen für richtig erachtet werden, die sich von den hier gemachten unterscheiden. Im Rahmen der in unserer Buchpublikation vorgelegten breiteren Analyse basieren die Form der Datenzusammenfassung und das vorgestellte Ergebnis auf den theoretischen Überlegungen zum konkreten Forschungsproblem und -feld der Kollektivsymbolik sowie den vorhergehenden empirischen Untersuchungen zu diesem Thema. Für die in diesem Artikel vorgestellte Typologisierung wurden wiederum fallweise Verschiebungen vorgenommen, die der hier gewählten Perspektive und detaillierten Untersuchung ausgewählter Wörter sowie der Frage nach Aktualitätsbezügen im gewonnenen Material geschuldet sind. Betrachten wir dieses also nun der Reihe nach im Hinblick auf beide Bereiche (Kollektivsymbolik wie auch deren Verhältnis zu im Interdiskurs auftauchenden Aktualitäten).

\subsection{Gesundheit}

Bereits die Liste der häufigsten Antworten (Tabelle 2a) deutet darauf hin, dass Gesundheit sowohl über einige eng(er) mit der Wortbedeutung verbundene Kategorien sowie den Hinweis auf entsprechende Lebensbereiche und Institutionen definiert ist (Wohlbefinden, Sport/Ernährung, Arzt etc.) als auch über solche, die zumindest auf eine zusätzliche breitere semantische Funktionalisierung vor dem Hintergrund der Kommunikation und Kollektivsymbole hinweisen. So wird sie nicht nur mit dem Joker wichtig, der selbstverständlich auf jegliche als besonders relevant eingestuften Größen anwendbar ist, charakterisiert (wie auch dem ähnlich gearteten höchstes Gut), sondern es treten bereits auf dieser Ebene wörtlich wiederholter Antworten Bezugsgrößen auf, die im Lexikon im Hinblick auf Gesundheit kaum zu finden wären - wie Glück, Freiheit, Freude und Sicherheit.

Generell lässt sich zugleich aber feststellen, dass nur die Antworten wichtig sowie Glück beim Blick auf wörtlich wiederholte Nennungen etwas deutlicher her- 
Tabelle 2a. Liste der häufigsten Antworten $(\mathrm{N} \geq 50)$ zur Charakterisierung der Bedeutung des Wortes Gesundheit (Deutschland 2020, 1002 Vpn)

\begin{tabular}{|l|r|l|r|}
\hline \multicolumn{4}{|c|}{ Gesundheit (N, 2020) } \\
\hline wichtig & 221 & höchstes Gut & 69 \\
\hline Glück & 152 & Arzt & 60 \\
\hline Leben & 94 & Sicherheit & 58 \\
\hline Freiheit & 78 & Ernährung & 51 \\
\hline Freude & 77 & Wohlbefinden & 50 \\
\hline Sport & 74 & & \\
\hline
\end{tabular}

vortreten, alle weiteren mindestens $50 \mathrm{Mal}$ auftretenden und also durch mindestens fünf Prozent der Befragten ${ }^{12}$ gleichlautend gemachten Nennungen liegen nur in einem mittleren Bereich. Die Konventionalisierung auf der sprachlichen Ebene ist somit eher schwach ausgeprägt.

Sieht man sich das Bild an, das sich nach einer weiteren Zusammenfassung zu breiter organisierten Dimensionen im semantischen Profil ergibt (Tabelle 2b), entstehen jedoch nochmals einige Verschiebungen und bestimmte Antwortgruppen treten deutlicher (bzw. überhaupt) hervor. Anhand einer reinen Häufigkeitsliste wären diese allenfalls auf unteren Plätzen oder gar im Bereich vereinzelt auftretender Nennungen verortet, so dass ihre Rolle vor dem Hintergrund der restlichen Nennungen nicht adäquat einzuschätzen wäre. Da ebendiese Rolle nun von Interesse ist, also die Bedeutung der jeweiligen Dimensionen vor dem Hintergrund aller zum jeweiligen Wort gemachten Nennungen, werden hier zusätzlich die prozentualen Anteile an den Antworten ausgewiesen.

Die neue Betrachtungsweise anhand des semantischen Profils verdeutlicht die starke Rolle einer Dimension, die sich auf konkrete Institutionen (Ärzte, Krankenhaus etc.) und Behandlungen (Medikamente) bezieht, welche an sich weniger den Zustand Gesundheit als den Krankheitsfall betreffen. Deutlich wird auch nochmals und noch stärker der große Anteil von Nennungen, die schlicht die Relevanz und den hohen Status des Wortes markieren - zusammengefasst machen die Dimensionen wichtig sowie höchstes/hohes Gut 13,1 Prozent aller Nennungen aus. Die klar kommunikativen Bedeutungen treten vor diesem Hintergrund im semantischen Profil etwas zurück, sie sind zugleich jedoch vielseitig organisiert und beziehen sich sowohl auf individualistische Lebensaspekte (Leben, Glück, keine Schmerzen) wie auch auf gesellschaftliche (Sport, Freiheit, Sicherheit).

12 Anhand der Basis von $\mathrm{N}=1002$ Vpn ergibt ein Verschieben des Kommas um eine Dezimalstelle nach links den prozentualen Anteile der Vpn, die die jeweilige Nennung gemacht haben. 
Tabelle 2b. Semantisches Profil* von Gesundheit (Deutschland 2020, 1002 Vpn) ${ }^{13}$

\begin{tabular}{|c|c|c|}
\hline Gesundheit (N 4215) & $\mathrm{N}$ & $\%$ \\
\hline $\begin{array}{l}\text { Institutionen: (83) Arzt 60, Ärzte 16, Arztbesuche 3, Ärztemangel, ärztliche Hilfe, } \\
\text { Ärztliche Untersuchung, ärztliche Versorgung; (31) Medikamente 26, Medikamente } \\
\text { bezahlbar, Medikamente nehmen müssen um die Gesundheit auf dem aktuellen } \\
\text { Zustand zu halten, Medikamente nur für Reiche, Medikamente zu erhalten, } \\
\text { medikamentenfrei; (41) Medizin 34, medizinische Versorgung 4, medizinischer } \\
\text { Fortschritt 3; (38) Krankenhaus 34, Krankenhäuser 4; (44) Krankenkasse 35, } \\
\text { Krankenversicherung 9; (35) Krankheit 31, Krankheit ist etwas furchtbares, } \\
\text { krankheitslos 3; (27) Pflege 17, pflegen 9, Pflegenotstand; Gesundheitssystem } 17\end{array}$ & 316 & 7,5 \\
\hline $\begin{array}{l}\text { wichtig } 221 \text {, sehr wichtig } 42 \text {, das wichtigste } 36 \text {, das wichtigste: im Leben } 9 \text {, } \\
\text { überhaupt } 5 \text {, das ein und alles 2; wichtig: damit man nicht in Krankenhäuser } \\
\text { muss, für Mensch Tier und Umwelt, fürs alles andere, um Arbeiten zu können, } \\
\text { um ganzheitlich zu evolutionieren, um leben zu können; wichtiger: als Geld } 8 \text {, als } \\
\text { Reichtum 2, Grundlage 2, als alles andere 2, denn je, Faktor, Teil des Lebens 2; } \\
\text { wichtigstes 2, Merkmal eines sorgenfreien Lebens; alles 14, alles: auf der Welt, } \\
\text { dafür tun, tun können, sonst ist alles nichts, am wichtigsten 3, am allerwichtigsten, } \\
\text { an erster Stelle } 2\end{array}$ & 314 & 7,4 \\
\hline $\begin{array}{l}\text { Leben 94, Lebensfreude } 25 \text {, leben } 24 \text {, Lebensqualität 23, langes Leben } 21 \text {, } \\
\text { lebensnotwendig } 8 \text {, lebendig } 7 \text {, Lebensstil 7, Lebensweise 7, lebenswichtig } 6 \text {, } \\
\text { Lebensmut 3, Lebenslust 2, Lebenserwartung 2, Lebensgefühl 2, lebenswert 2, } \\
\text { Leben genießen, Leben können, leben ohne Probleme, leben so dass man gesund } \\
\text { bleibt, Lebensenergie, Lebensgrundlage, Lebensrecht }\end{array}$ & 240 & 5,7 \\
\hline $\begin{array}{l}\text { (149) höchstes Gut 69, hohes Gut 14, kostbar 4, kostbares Gut 2, wichtigstes: Gut } \\
\text { 18, Gut des Menschen 2, wichtiges Gut 6, wertvolles Gut 4, das heiligste Gut, } \\
\text { ein sehr wichtiges Gut, ein Volksgut, erstrebenswertes Gut, wertvoll 26; (75) gut } \\
\text { 32, gut: fühlen 2, gehen 2, genährt 2, versorgt, versorgt in Deutschland, verwaltet } \\
\text { bei uns, wenn man gesund ist; gute/-er Absicherung, Appetit, Ärzte, Betreuung, } \\
\text { Doktoren, Förderung, Gedanken, Krankheitsvorsorge, Laune 2, Lebensmittel, } \\
\text { Lebensqualität, Medizin, Psyche, Versorgung 3, Vorsorge, Service, Umgang mit } \\
\text { dem Körper; gutes: Aussehen, Gefühl 4, Gut, Leben 5, gutgehen }\end{array}$ & 224 & 5,3 \\
\hline Glück 152, glücklich 42, höchstes Glück & 195 & 4,6 \\
\hline $\begin{array}{l}\text { Sport 74, Sport treiben } 6 \text {, sportlich 5; Fitness } 31 \text {, fit 26; Bewegung } 15 \text {, } \\
\text { Beweglichkeit } 6 \text {, Bewegungsfreiheit 4; aktiv 13, Aktivität } 7\end{array}$ & 187 & 4,4 \\
\hline $\begin{array}{l}\text { Wohlbefinden } 50 \text {, wohlfühlen } 46 \text {, Wohlergehen } 13 \text {, wohlbehalten } 7 \text {, Wohlsein } 4 \text {, } \\
\text { Wohlbehagen } 3 \text {, Wohl } 2\end{array}$ & 125 & 3,0 \\
\hline Freiheit 78 , frei 13 , frei sein 7 & 98 & 2,3 \\
\hline Freude & 77 & 1,8 \\
\hline Zufriedenheit 47, zufrieden 21 & 68 & 1,6 \\
\hline Sicherheit 58, sicher 4 & 62 & 1,5 \\
\hline
\end{tabular}

13 1. In der Tabelle fett gesetzte Wörter wurden aufgrund der Daten aus der aktuellen Erhebung für das jeweilige Land als Kollektivsymbole eingestuft. 2. Aufgrund der besonderen/spezifischen Zielsetzung der hier vorgestellten Auswertung wurden fallweise andere Zuordnungen einzelner Antworten vorgenommen, so dass (minimale) Abweichungen der Anteile einiger Dimensionen im Vergleich zu unserer überblickenden Publikation entstehen. 


\begin{tabular}{|l|c|c|}
\hline \multicolumn{1}{|c|}{ Gesundheit (N 4215) } & N & $\%$ \\
\hline keine Schmerzen 21, nicht krank 17, keine Krankheit 14, frei von Krankheit 2 & 54 & 1,3 \\
\hline Ernährung & 51 & 1,2 \\
\hline $\begin{array}{l}\text { gesund 14, gesund ernähren 10, gesund leben 8, gesund sein 4, Gesundheit } \\
\text { 2, Gesundheitsvorsorge 2, gesunde Menschen glückliche Menschen, gesunde } \\
\text { ausgeglichene Ernährung pflegen, gesunder Schlaf, Gesundheit aller Menschen } \\
\text { bedeutsam siehe aktuelle Coronakrise; Gesundheit: erhalten, für den Menschen } \\
\text { existentiell, ist das höchste gut, ist wichtiger als Geld, zu erhalten ist wichtig }\end{array}$ & 49 & 1,2 \\
\hline Familie & 45 & 1,1 \\
\hline Alter 29, alt werden 7, alt 3 & 39 & 0,9 \\
\hline $\begin{array}{l}\text { Corona 20, Coronavirus 3, Coronakrise 2, Covid 19 3, Angst vor Krebs (und } \\
\text { Corona), Corona lässt grüßen, CORONA TIME, Corona vermeiden, Gegenteil von } \\
\text { Corona }\end{array}$ & 31 & 0,7 \\
\hline
\end{tabular}

* Die semantischen Profile zeigen die Dimensionen, die mindestens rund 1\% aller gemachten Nennungen (im Hinblick auf das Wort, dessen Bedeutung charakterisiert wurde) auf sich vereinigen.

Es zeigt sich, dass wir es mit einem breiten Profil zu tun haben, in dem kommunikative Bedeutungen eine wesentliche Rolle spielen, wobei jedoch keine einzelne der entsprechenden Dimensionen (bis auf Leben) so ausgeprägt ist, dass ihr eine besondere Position oder gar der Status eines Alleinstellungsmerkmals in der Semantik zuzusprechen wäre. Diese breit aufgestellte, über lexikalische Bedeutungen und lebenspraktische Bezüge hinausgehende Semantik spricht, zusammengenommen mit der klaren Einstufung des Wortes in der Bewertungshierarchie, für das Vorliegen eines Kollektivsymbols, welches in Kommunikationen aufgrund seiner stabil und vielfältig ausgebauten Bedeutungen ebenso vielfältige Anschlüsse an die unterschiedlichsten Bereiche ermöglicht und so in verschiedenen Kontexten einsetz- bzw. funktionalisierbar wird.

Vor dem Hintergrund des eingangs erwähnten speziellen Untersuchungsinteresses, das sich derzeit im Hinblick auf die Coronapandemie ergibt, wird das Augenmerk nun noch auf die Frage gerichtet, ob und wie zum Befragungszeitpunkt, also noch zu Beginn der Pandemie, als diese jedoch durchaus in den Medien und in der Öffentlichkeit bereits breite Aufmerksamkeit erhielt, auf die aktuelle Situation Bezug genommen wird. Dafür wurde das Material nochmals speziell dahingehend analysiert, wie viele Antworten (hier - im Hinblick auf Gesundheit) sich, zusammen mit den oben bereits abgebildeten wörtlichen Corona-Bezügen, auf die aktuelle Situation beziehen. Wie stellen sich also (zum Erhebungszeitpunkt noch kurzfristig) vorhandene Aktualitäten vor dem Hintergrund des Gesamtprofils dar?

Wie zu sehen, wächst der Anteil entsprechender Bezüge durch die Einbeziehung weiterer möglicher Antwort-Aspekte nicht nennenswert an. Selbst wenn man die anhand von Einzelantworten erkennbare Möglichkeit der (äußerst indirekten und nur potentiell gegebenen) Bezugnahme auf die Pandemie im Rahmen 
Tabelle 2c. Charakterisierung der Bedeutung von Gesundheit - Bezüge auf Corona, Pandemie, aktuelle Situation etc.

\begin{tabular}{|l|l|r|r|}
\hline \multicolumn{1}{|c|}{ Kategorie } & \multicolumn{1}{|c|}{ Nennungen (N gesamt 4215) } & N & \% v. N \\
\hline $\begin{array}{l}\text { Bezüge auf Corona, } \\
\text { Virus, Pandemie }\end{array}$ & $\begin{array}{l}\text { Corona 17, Coronakrise 2, Angst vor Krebs (und Corona), } \\
\text { Corona lässt grüßen, CORONA TIME, Corona vermeiden, } \\
\text { Gegenteil von Corona } \\
\text { Coronavirus 3, kein Coronavirus 2, ohne Virus, Virus } \\
\text { Covid 19 3 } \\
\text { Pandemie 3 } \\
\text { kein Ausgehverbot }\end{array}$ & 38 & 0,9 \\
\hline $\begin{array}{l}\text { Bezüge auf den } \\
\text { aktuellen Moment }\end{array}$ & $\begin{array}{l}\text { aktuell, aktueller Wunsch; Gesundheit aller Menschen } \\
\text { bedeutsam, siehe aktuelle Coronakrise } \\
\text { gerade jetzt wichtig, jetzt gerade das wichtigste } \\
\text { ganz wichtig in der heutigen Zeit wegen Coronavirus, in } \\
\text { heutiger Zeit angeschlagen, zur Zeit das Thema } \\
\text { im Moment leider bedroht weltweit }\end{array}$ & 9 & 0,2 \\
\hline \multicolumn{1}{|c|c|c|}{ Summe } & 47 & 1,1 \\
\hline
\end{tabular}

von Nennungen mit globalen Bezügen berücksichtigt, stellt sich heraus, dass die Antworten, in denen auf ,die Welt“ Bezug genommen wird, im Wesentlichen auf phraseologisierte Wendungen zurückgehen und keinen aktuellen Bezug erkennen lassen. ${ }^{13}$ So oder so ergibt sich für die Aktualitätsbezüge zum hier interessierenden Thema (zumindest im Hinblick auf das Wort Gesundheit) auch bei gezielter Analyse weiterhin ein Anteil von nur rund einem Prozent an den Antworten. Das Gewicht entsprechender Antworten vor dem Hintergrund des Gesamtprofils bleibt also selbst bei deren gesonderter Betrachtung bzw. breiterer Zusammenfassung weitgehend unverändert.

\subsection{Zdrowie}

Im Fall von zdrowie ist die Lage ähnlich. Die Liste der häufigsten Antworten zeigt zunächst ein prinzipiell ähnlich gestaltetes Bild, indem zum einen auf lexikalische sowie institutionelle und lebenspraktische Bedeutungen des Wortes verwiesen wird, zum anderen aber auch kommunikative/kollektivsymbolische Komponenten auftauchen. Diese stehen hier mit szczęście/Glück und radość/Freude sogar an erster Stelle und werden am häufigsten wiederholt genannt. Lexeme, die Gesundheit bzw. deren Fehlen, also den Krankheitsfall, betreffen (lekarz, szpital, leki / Arzt,

13 Globale Bezüge / auf die „Welt“ bezogene Phraseologismen und Wendungen (je 1): kaputtes Gesundheitssystem weltweit, in dieser Welt gefährdet, [im Moment leider bedroht] weltweit, alles auf der Welt, das wichtigste Gut auf der Welt, die Welt, hohes Gut der Welt, kann man mit allem Geld der Welt nicht kaufen. 
Krankenhaus, Medikamente) stehen erst im mittleren bis unteren Bereich, ebenso die direkte Charakterisierung von Gesundheit über die bipolare Opposition keine Krankheiten, keine Krankheit.

Tabelle 3a. Liste der häufigsten Antworten $(\mathrm{N} \geq 50)$ zur Charakterisierung der Bedeutung des Wortes zdrowie (Polen 2020, 1000 Vpn)

\begin{tabular}{|l|r|l|r|l|r|}
\hline \multicolumn{5}{|c|}{ zdrowie / Gesundheit (N, 2020) } \\
\hline szczęście / Glück & 240 & lekarz / Arzt & 87 & $\begin{array}{l}\text { kondycja / Kondition/ } \\
\text { körperl. Verfassung }\end{array}$ & 57 \\
\hline radość / Freude & 232 & życie / Leben & 76 & witalność / Vitalität & 53 \\
\hline siła / Kraft & 131 & dobro / d. Gute & 67 & leki / Medikament & 52 \\
\hline spokój / Ruhe & 108 & $\begin{array}{l}\text { brak chorób / k. } \\
\text { Krankheiten }\end{array}$ & 62 & $\begin{array}{l}\text { brak choroby / k. } \\
\text { Krankheit }\end{array}$ & 52 \\
\hline $\begin{array}{l}\text { dobre samopoczucie / } \\
\text { gutes Wohlbefinden }\end{array}$ & 105 & szpital / Krankenhaus & 59 & Sport & 50 \\
\hline
\end{tabular}

Tabelle 3b. Semantisches Profil* von zdrowie (Polen 2020, 1000 Vpn)

\begin{tabular}{|l|c|c|}
\hline \multicolumn{1}{|c|}{ zdrowie / Gesundheit (N 4159) } & $\mathrm{N}$ & $\%$ \\
\hline $\begin{array}{l}\text { służba zdrowia / Gesundheitssystem: lekarz 87, lekarze 11, leki 52, lekarstwa 29, } \\
\text { medycyna 11; opieka 7, opieka medyczna 2; pielegniarka 8, służba zdrowia 9; } \\
\text { szpital 59, apteka 17, NFZ 15, tabletki 6, farmacja; profilaktyka 9 }\end{array}$ & 323 & 7,8 \\
\hline $\begin{array}{l}\text { dobre x / gutes x: dobre samopoczucie 105, dobra/-e/-y: kondycja 14, forma 11, } \\
\text { wyniki 5, humor 4, odżywianie 4, stan 4, życie 3, nastrój 3, stan ducha 2, stan } \\
\text { fizyczny, stan psychiczny, kondycja psychofizyczna, zwyczaje, los, wygląd; dobro } \\
\text { 67, dobrobyt 18, dobrostan 14, dobroć 6; samopoczucie 37 }\end{array}$ & 303 & 7,3 \\
\hline radość / Freude 232, radość z życia 7; uśmiech 53, uśmiech na twarzy & & \\
\hline szczęście / Glück 240, szczęśliwy 4, szczęście niedoceniane; zadowolenie 41 & 286 & 7,0 \\
\hline $\begin{array}{l}\text { kondycja / Kondition/körperl. Verfassung 57, kondycja fizyczna, kondycja } \\
\text { psychiczna; witalność 53, witalizm 4; wigor 19; forma 19; krzepa 18, krzepkość 4; } \\
\text { tężyzna 6, tężyzna fizyczna 3; energia 41 }\end{array}$ & 226 & 5,4 \\
\hline $\begin{array}{l}\text { brak x / kein x: brak chorób / keine Krankheiten 62, brak choroby 52; brak: bólu } \\
\text { 26, zmartwień 13, problemów 10, cierpienia 5, ograniczeń 4, dolegliwości 3, } \\
\text { lekarstw 3, lekarzy 3, trosk 3, wydatków 3, leków 2, objawów choroby 2, stresu 2, } \\
\text { konieczności kontaktów ze służbą zdrowia 2, rozpaczy, alkoholu, barier, bolączek, } \\
\text { dbałości, depresji, dodatkowych kosztów, fizycznego bólu, gorączki, kalectwa, kaszlu, } \\
\text { konieczności przyjmowania lekarstw, kontuzji, kościoła, mi go, nałogów, NFZ, } \\
\text { niepokoju, ograniczeń zawodowych, papierosów, pobytu w szpitalu, polityki, potrzeby } \\
\text { chodzenia do lekarza, profilaktyki zdrowia, przeszkód, schorzeń, wizyt u lekarzy, } \\
\text { zaburzeń, zainteresowania wszystkich kolejnych rządów, zażywania lekarstw }\end{array}$ & 225 & 5,4 \\
\hline $\begin{array}{l}\text { sport/dieta / Sport/Ernährung: sport 50, ruch 17, ćwiczenia 8, bieg, bieg po zdrowie, } \\
\text { gimnastyka 2, aktywność 14, aktywność fizyczna 7, aktywny tryb życia; dieta 21, } \\
\text { witaminy 19, zdrowe odżywianie 10, zdrowa żywność 7, jedzenie 8, odżywianie 7, } \\
\text { żywność 3, owoce 6, warzywa 4, warzywa i owoce }\end{array}$ & 187 & 4,5 \\
\hline
\end{tabular}




\begin{tabular}{|l|r|c|}
\hline \multicolumn{1}{|c|}{ zdrowie / Gesundheit (N 4159) } & \multicolumn{1}{c|}{ N } & $\%$ \\
\hline siła / Kraft 131, siła: ducha, fizyczna, psychiczna, walki, witalna; moc 30 & 166 & 4,0 \\
\hline spokój / Ruhe 108, spokój ducha 3, spokój wewnętrzny, spokojne życie & 113 & 2,7 \\
\hline życie / Leben 76, żywotność 10 & 86 & 2,1 \\
\hline rodzina / Familie 49, dom / Haus 13 & 62 & 1,5 \\
\hline choroba / Krankheit & 47 & 1,1 \\
\hline
\end{tabular}

Das semantische Profil für $z$ drowie/Gesundheit stellt sich wiederum etwas anders dar als die pure Liste häufiger Nennungen. Die Gruppierung der Antworten zu Dimensionen ergibt auch hier ein Bild, in dem institutionelle Aspekte nach oben rücken, wobei, wie zu sehen, die zusammenfassende Bezeichnung stużba zdrowia (welche als Entsprechung für Gesundheitssystem gesehen werden kann), zwar nicht wörtlich auftaucht, jedoch durch die hier zusammengefassten Nennungen auf diesen Gesamtbereich hingewiesen wird. Auch kommunikative Bedeutungskomponenten stehen weiterhin vorne - außer den bereits genannten szczęście/Glück und radość/Freude insbesondere dobre x sowie siła und spokój (Kraft und Ruhe), mit etwas niedrigerem Anteil.

Im Vergleich lassen sich einige interessante Überschneidungen und Unterschiede des deutschen und polnischen Profils feststellen. Dabei sind manche Ähnlichkeiten auf den ersten Blick sichtbar, andere hingegen erscheinen erst, wenn über eine rein lexikalische Ebene hinaus nach Gemeinsamkeiten geschaut wird, die sich auf die Strategien beziehen, welche bei der Charakterisierung der Bedeutung angewendet werden. So steht in beiden Profilen nicht nur, wie erwähnt, eine (breit gefasste) institutionelle Dimension im Vordergrund, sondern es kommen auch darüber hinaus nicht wenige weitere gemeinsame Bezugsbereiche bzw. entsprechende Komponenten vor - darunter Leben, Glück, Sport/Ernährung sowie Gut/dobro; diese haben jedoch teils unterschiedlichen Anteil am jeweiligen Gesamtprofil. Ähnlichkeiten im Hinblick auf den zweitgenannten Aspekt (Strategien) betreffen zum einen die (in beiden Gesamtprofilen hervorstechende) Anwendung eines kommunikativen Jokers (in Deutschland - wichtig, in Polen - dobre x), zum anderen die erwähnte bipolare Definition von Gesundheit durch das Fehlen von Krankheit (was in den polnischen Antworten mehr Raum einnimmt). Ebenfalls interessant ist das Auftauchen unterschiedlicher Kollektivsymbole (sowie kollektivsymbolischer Katalysatoren) in beiden semantischen Profilen - wenn auch jeweils eher auf den hinteren Plätzen - in beiden Fällen sind dies Familie/rodzina und Krankheit ${ }^{14}$ / choroba sowie, darüber hinaus, Sicherheit und Freiheit in Deutschland sowie in Polen - dobro, dom.

Die Corona-Thematik taucht in den polnischen Antworten zu zdrowie nicht ausreichend häufig auf, um Eingang ins semantische Profil zu finden. Eine detail-

${ }^{14}$ In Deutschland als Katalysator eingestuft. 
lierte Analyse zeigt, dass dies selbst bei einer Zusammenfassung aller Antworten mit (sichtbarem) Bezug auf entsprechende Aktualitäten so bleibt (Tabelle 3c). Auch hier spielen globale Bezüge keine Rolle. ${ }^{15}$

Tabelle 3c. Charakterisierung der Bedeutung von zdrowie - Bezüge auf Corona, Pandemie, aktuelle Situation etc.

\begin{tabular}{|l|l|r|r|}
\hline \multicolumn{1}{|c|}{ Kategorie } & \multicolumn{1}{|c|}{ Nennungen (N gesamt 4159) } & N & \% v. N \\
\hline $\begin{array}{l}\text { Bezüge auf Corona, } \\
\text { Virus, Pandemie }\end{array}$ & $\begin{array}{l}\text { koronawirus 8, coronawirus } \\
\text { wirus 3 } \\
\text { teraz b. ważne - bo wirus szaleje } \\
\text { pandemia } \\
\text { koniec epidemii }\end{array}$ & 15 & 0,36 \\
\hline $\begin{array}{l}\text { Bezüge auf den } \\
\text { aktuellen Moment }\end{array}$ & $\begin{array}{l}\text { jest najważniejsze zawsze i wszędzie, dlatego teraz lepiej } \\
\text { \#zostaćwdomu; można wychodzić z domu [potentieller } \\
\text { Bezug] }\end{array}$ & 2 & 0,05 \\
\hline & \multicolumn{1}{|c|}{ Summe } & 17 & 0,41 \\
\hline
\end{tabular}

\subsection{Krankheit}

Durchaus deutlicher werden die Bezüge auf die Corona-Thematik in beiden Erhebungen im Hinblick auf die Wörter Krankheit/choroba. Im Fall der deutschen Antworten schafft Corona es dabei gar auf die Liste der häufigsten wörtlich wiederholten Nennungen, wie die folgende Tabelle zeigt. Jedoch ist insgesamt auch hier die Ausprägung einzelner, wiederholt gemachter Nennungen nicht so deutlich, dass aus dieser Perspektive deren Gewicht vor dem Hintergrund der restlichen Antworten erkennbar würde. Betrachten wir daher direkt auch das semantische Profil, welches dies zusätzlich und besser aufzeigen kann.

Tabelle 4a. Liste der häufigsten Antworten $(\mathrm{N} \geq 50)$ zur Charakterisierung der Bedeutung des Wortes Krankheit (Deutschland 2020, 1002 Vpn)

\begin{tabular}{|l|r|l|r|}
\hline \multicolumn{3}{|c|}{ Krankheit (N, 2020) } \\
\hline Angst & 165 & schlimm & 65 \\
\hline Tod & 148 & Corona & 60 \\
\hline Krankenhaus & 127 & Medikamente & 61 \\
\hline Schlecht & 123 & Schmerz & 57 \\
\hline Arzt & 124 & Medizin & 52 \\
\hline Schmerzen & 120 & Trauer & 44 \\
\hline Hilfe & 85 & & \\
\hline
\end{tabular}

15 Einzige auf die „Welt“ bezogene phraseologische Wendung: najważniejsza rzecz na świecie. 
Tabelle 4b. Semantisches Profil* von Krankheit (Deutschland 2020, 1002 Vpn)

\begin{tabular}{|c|c|c|}
\hline Krankheit (N 4260) & $\mathrm{N}$ & $\%$ \\
\hline Schmerzen 120, Schmerz 57, schmerzhaft 3, Schmerzensgeld; Leid 36, Leiden 39 & 256 & 6,0 \\
\hline $\begin{array}{l}\text { Arzt 124, Ärzte 25, Arztbesuch 4, Ärtztemangel, Ärzte aufsuchen, Ärzte ratlos, } \\
\text { Ärzteabwanderung, Ärztemangel, Ärztesystem, ärztliche Hilfe, ärztliche Kunst, } \\
\text { ärztliche Versorgung; Doktor 2, Hausarzt, Zahnarzt, Mediziner; Pflege 32, } \\
\text { pflegen 2, Pfleger 2, Pfegekräfte Mangel, pflegebedürftig, Pflegefall, Pflegeheim, } \\
\text { Pflegenotstand, Pflegepersonal }\end{array}$ & 209 & 4,9 \\
\hline $\begin{array}{l}\text { schlecht 123, schlechtes Leben 3, schlecht gehen 3, schlechte Gesundheit 2, } \\
\text { schlechte Lebensqualität 2, schlecht fühlen, schlechte Ernährung, schlechte } \\
\text { Vorsorge, Schlechtes, schlechtes Gefühl, schlechtes System; schlimm 65, schlimm } \\
\text { für die Betroffenen, schlimme Diagnose, schlimme Sache }\end{array}$ & 207 & 4,9 \\
\hline $\begin{array}{l}\text { Tod 148, tot } 6 \text {, tödlich } 7 \text {, Todesangst } 2 \text {, todbringend, Todesdrohung; Sterben } 21 \text {, } \\
\text { Sterblichkeit } 2\end{array}$ & 188 & 4,4 \\
\hline $\begin{array}{l}\text { Krankenhaus 127, Krankenhäuser 3, Klinik 7; Krankenkasse 15, } \\
\text { Krankenversicherung 4, Krankenschein 3, Krankengeld 2; krank 9, Krankheit } \\
\text { 3, kränklich 2; Krankenpflege 2, Krankenschwester 2, Krankenhauskeime 2, } \\
\text { Krank darf man nicht werden, Krankenhausleistungen, Krankenhausnotstand, } \\
\text { Krankenwagen, Krankheit wird sich ändern }\end{array}$ & 186 & 4,4 \\
\hline $\begin{array}{l}\text { Angst 165, Ängste 8, Angst sein Leben zu verlieren, Angst vor Corona und } \\
\text { Ansteckungsgefahr, Angst vor Krankenhäusern und der Pharmaindustrie, Angst vor } \\
\text { Schmerzen, Angst vor schweren Krankheiten, Angst vor Tod, angsteinflössend }\end{array}$ & 180 & 4,2 \\
\hline $\begin{array}{l}\text { Hilfe } 85 \text {, Hilflosigkeit 23, hilflos } 18 \text {, hilfsbedürftig } 7 \text {, Hilfsbedürftigkeit 4, Hilfe } \\
\text { benötigen } 3 \text {, Hilfe angewiesen, Hilfe erforderlich, Hilfe suchen, Hilfe von anderen, } \\
\text { Hilfe von Familie, Hilfestellung, Hilfsmöglichkeit verstärken }\end{array}$ & 147 & 3,5 \\
\hline $\begin{array}{l}\text { Beschwerden 9, Beshwerden; Fieber 13, Fieber und Hausarrest, Schnupfen } 8 \text {; } \\
\text { Unwohlsein 35, unwohl 12, unwohl fühlen 2; chronisch 10, Chroniker 2, chronische } \\
\text { Beschwerden, chronische Krankheit; Gebrechen 10, gebrechlich 2; Schwäche 13, } \\
\text { schwach 9, schwächt } 2\end{array}$ & 132 & 3,1 \\
\hline $\begin{array}{l}\text { Medikamente 61, Medikamente/Behandlung, Medikamentenwangel, } \\
\text { Medikamentenzuzahlung, medikamentös behandelt; Medizin 52, Medizin nehmen, } \\
\text { Medizin und Ärzte, medizinische Versorgung 2, medizinischer Fortschritt }\end{array}$ & 122 & 2,9 \\
\hline $\begin{array}{l}\text { Corona 60, Coronavirus 8, Covid } 19 \text { 6; Virus 18, Viren 7, Vieren sind die neue } \\
\text { Krankheit, Viren/Bakterien; Pandemie 10, Seuche } 6\end{array}$ & 117 & 2,7 \\
\hline Trauer 44, traurig 43, Traurigkeit 15 & 102 & 2,4 \\
\hline $\begin{array}{l}\text { Gesundheit } 43 \text {, gesund 5, gesund werden } 5 \text {, gesunden } 3 \text {, gesund ernähren 2, gesund } \\
\text { leben } 2 \text {, gesund bleiben, gesund sein ist besser, gesunde Lebensweise, Gesundheit } \\
\text { ist besser als viele Krankheiten, Gesundheit ist wichtig, Gesundheitsverlust 2, } \\
\text { Gesundheitsbeeinträchtigung, gesundheitsgefährdend; Gesundheitssystem 15, } \\
\text { Gesundheitswesen 2, Gesundheitspolitik }\end{array}$ & 87 & 2,0 \\
\hline $\begin{array}{l}\text { Einschränkung 32, Einschränkungen 17, eingeschränkt 9, einschränkend 7, } \\
\text { eingeschränkt sein 3, eingeschränkte Lebensqualität, eingeschränkte Möglichkeiten, } \\
\text { eingeschränktes Leben, Eingeschränktheit im Tagesablauf, Einschränkung der } \\
\text { Freiheit, Einschränkung der Lebensqualität, Einschränkungen im Alltag, Einengung }\end{array}$ & 76 & 1,8 \\
\hline
\end{tabular}




\begin{tabular}{|l|r|r|}
\hline Heilung 22, heilbar 10, heilen 10, Heilkunde; Genesung 26 & 69 & 1,6 \\
\hline $\begin{array}{l}\text { nicht: gut 16, gesund 10, schön 4, wünschenswert 3, wohlfühlen 2, mobil 2, } \\
\text { arbeiten können 2, heilbar 3, anerkannt, aufgeben, aufkommen lassen, einfach, fit, } \\
\text { gewollt 2, lebenswert, leistungsfähig, mehr frei, notwendig, ok, vital, zu ändern, } \\
\text { zufrieden, zur Arbeit gehen können, nichts gutes }\end{array}$ & 59 & 1,4 \\
\hline Sorge 33, Sorgen 24, sorgenvoll & 58 & 1,4 \\
\hline $\begin{array}{l}\text { Geld 19, Geldsorgen 6, Geldnot 4, geldabhängige Genesung (teils); Kosten 17, } \\
\text { kostet Kraft, kostet Lebensqualität, kostspielig }\end{array}$ & 50 & 1,2 \\
\hline
\end{tabular}

Wie zu sehen, nimmt eine entsprechende breitere Dimension mit wörtlichen Bezügen auf Corona, die Pandemie u.ä. hier einen Platz im unteren Mittelfeld ein. Darüber hinaus und insgesamt ist das semantische Profil für das Wort Krankheit geprägt durch die Unterstreichung negativer Aspekte aus einer die individuelle Sphäre betreffenden Sicht (Schmerzen, schlecht, Angst, Beschwerden etc.; auch einige wenige sozusagen hoffnungsvollere Dimensionen sind aus dieser Perspektive formuliert - z.B. Hilfe, Heilung); hinzu kommen Dimensionen mit institutionellem und medizinischem Bezug (Arzt/Ärzte, Krankenhaus, Medikamente). Interessant ist das Auftreten des finanziellen Aspekts im deutschen Profil, der, wenn auch mit geringem Anteil, eine eigene Dimension bildet, dabei jedoch wiederum die vorrangig eingenommene individuelle Perspektive unterstreicht (und nicht etwa gesellschaftliche/systemische Ursprünge von Geldsorgen im Krankheitsfall). Systemische Aspekte in einer breiteren, gesellschaftlichen Perspektive tauchen im Profil auch ansonsten nur sehr vereinzelt auf. Insgesamt sind nur wenige klar kommunikative Bedeutungen festzustellen - die Verknüpfung mit anderen Kollektivsymbolen ist eher schwach ausgeprägt und scheint eher logisch-praktisch motiviert zu sein (Hilfe, sowie die wechselseitige, bipolare Definition Gesundheit-Krankheit).

Tabelle 4c. Charakterisierung der Bedeutung von Krankheit - Bezüge auf Corona, Pandemie, aktuelle Situation etc.

\begin{tabular}{|l|l|c|c|}
\hline \multicolumn{1}{|c|}{ Kategorie } & \multicolumn{1}{|c|}{ Nennungen (N gesamt 4260) } & N & $\begin{array}{c}\text { \% v. } \\
\mathrm{N}\end{array}$ \\
\hline $\begin{array}{l}\text { Bezüge auf Corona, } \\
\text { Virus, Pandemie }\end{array}$ & $\begin{array}{l}\text { Corona 59, Coronavirus 7, Angst vor Corona und } \\
\text { Ansteckungsgefahr, Corona-Virus, zur Zeit koronavirus } \\
\text { Covid-19 4, Covid 2 } \\
\text { Pandemie 10, Seuche 4 } \\
\text { Virus (?) 18, Viren 7, Hysterievirus, neuzeitliche Viren, } \\
\text { Vieren sind die neue Krankheit, Viren/Bakterien }\end{array}$ & 118 & 2,77 \\
\hline $\begin{array}{l}\text { Bezüge auf den } \\
\text { aktuellen Moment }\end{array}$ & $\begin{array}{l}\text { aktuell 5; aktuell !, schrenkt uns aktuell alle in unserer } \\
\text { Bewegungsfreiheit ein (Corona), zur Zeit sehr aktuell } \\
\text { zur Zeit überall, zur Zeit Thema Nr. 1 }\end{array}$ & 10 & 0,23 \\
\hline \multicolumn{1}{|c|}{ Summe } & 128 & 3,0 \\
\hline
\end{tabular}


Aus diesem Grund wurde Krankheit vor dem Hintergrund der Gesamtdatenlage in Deutschland als Katalysator eingestuft; das hier im Vergleich zu Gesundheit etwas stärkere Auftauchen von Aktualitäten untermauert dies (auch im Zeitverlauf - im Jahr 1994 wurde in der ersten Untersuchung entsprechend auf AIDS/ das HIV-Virus verwiesen).

Nichtsdestotrotz bewegen sich, wie in Tabelle $4 \mathrm{c}$ zu sehen, auch hier die Hinweise auf die beginnende Pandemie in einem unteren Bereich, wenn es um deren Anteil am gesamten semantischen Profil geht. Die Einbeziehung weiterer direkter Bezüge auf den aktuellen Zeitpunkt kann dieses Bild, wie bereits im Hinblick auf das Wort Gesundheit, nicht wesentlich verändern. Der Löwenanteil der Semantik bezieht sich somit auf andere Größen, die im wesentlichen den Bereich persönlicher Empfindungen und Konsequenzen oder des Kontaktes mit entsprechenden Institutionen betreffen und sozusagen kaum „saisonalen Schwankungen“ unterliegen.

\subsection{Choroba}

Für choroba ergibt sich ein in Teilen ähnliches Bild, in dem jedoch einige wesentliche Akzente anders gesetzt sind. Bereits die Liste der häufigsten Antworten weist darauf hin, dass die Bedeutungen schon auf der lexikalischen Ebene breiter und stabiler ausgebaut sind; dies wird im semantischen Profil noch deutlicher.

Tabelle 5a. Liste der häufigsten Antworten $(\mathrm{N} \geq 50)$ zur Charakterisierung der Bedeutung des Wortes choroba (Polen 2020, 1000 Vpn)

\begin{tabular}{|l|c|l|r|l|r|}
\hline \multicolumn{5}{|c|}{ choroba / Krankheit (N, 2020) } \\
\hline ból / Schmerz & 273 & cierpienie / Leiden & 105 & $\begin{array}{l}\text { lekarstwa / } \\
\text { Medikamente }\end{array}$ & 62 \\
\hline smutek / Traurigkeit & 243 & $\begin{array}{l}\text { złe samopoczucie / } \\
\text { schlechtes Befinden }\end{array}$ & 95 & $\begin{array}{l}\text { bezsilność / Macht- / } \\
\text { Hilflosigkeit }\end{array}$ & 59 \\
\hline szpital / Krankenhaus & 149 & lekarz / Arzt & 88 & słabość / Schwäche & 55 \\
\hline śmierć / Tod & 140 & niemoc / Erschöpfung & 79 & nieszczęście / Unglück & 53 \\
\hline leki / Medikamente & 128 & $\begin{array}{l}\text { brak zdrowia / k. } \\
\text { Gesundheit }\end{array}$ & 74 & gorączka / Fieber & 47 \\
\hline strach / Angst & 114 & bieda / Armut & 69 & & \\
\hline
\end{tabular}

Wie im Profil zu sehen, werden auch hier viele formale Kategorien zur Charakterisierung der Bedeutung herangezogen (Symptome und Folgen von Krankheit betreffend), wobei vielfach eine individualistische Perspektive eingenommen wird. Darüber hinaus tauchen jedoch Antworten auf, die auf eine breitere, kommunikativ bedingte Einsetzbarkeit im Hinblick auf gesellschaftliche (nicht medizinische) Phänomene verweisen. Chory/krank kann danach nicht nur ein Mensch sein, son- 
Tabelle 5b. Semantisches Profil* von choroba (Polen 2020, 1000 Vpn)

\begin{tabular}{|c|c|c|}
\hline choroba / Krankheit (N 4492) & $\mathrm{N}$ & $\%$ \\
\hline $\begin{array}{l}\text { objawy/Symptome: złe samopoczucie } 95 \text {, niemoc } 79 \text {, gorączka } 47 \text {, osłabienie } 41 \text {, } \\
\text { depresja } 23 \text {, łóżko } 17 \text {, kaszel } 16 \text {, przygnębienie } 15 \text {, niedyspozycja } 14 \text {, temperatura } \\
\text { 13, katar } 9 \text {, wyczerpanie } 7 \text {, leżenie } 7 \text {, leżenie w łóżku } 6 \text {, zakażenie } 6 \text {, osłabiona } \\
\text { odporność, zaburzenie } 8 \text {, zaburzenia: funkcji organizmu, organizmu } 2 \text {, psychiczne, } \\
\text { zdrowotne, funkcji } 2 \text {, homeostazy; dolegliwość } 34 \text {, dolegliwości: organizmu, } \\
\text { bólowe, ciała, psychiczne; słabość } 55 \text {, słabe samopoczucie } 3 \text {, słaby organizm } 2 \text {, } \\
\text { słabe zdrowie }\end{array}$ & 520 & 11,6 \\
\hline $\begin{array}{l}\text { skutki/Folgen: cierpienie } 105 \text {, bezsilność } 59 \text {, nieszczęście } 53 \text {, bezradność } \\
\text { 43, samotność } 39 \text {, lęk } 37 \text {, niepewność } 36 \text {, płacz } 26 \text {, rozpacz } 23 \text {, niepokój } 21 \text {, } \\
\text { niepełnosprawność } 19 \text {, stres } 19 \text {, izolacja } 16 \text {, beznadzieja } 10\end{array}$ & 506 & 11,3 \\
\hline $\begin{array}{l}\text { służba zdrowia/Gesundheitssystem: szpital 149, leki 128, lekarstwa } 62 \text {, lekarz } 88 \text {, } \\
\text { leczenie } 42 \text {, opieka 20, apteka } 13\end{array}$ & 502 & 11,2 \\
\hline $\begin{array}{l}\text { ból/Schmerz 273, ból: głowy 5, fizyczny 2, fizyczny i psychiczny, gardła, } \\
\text { i gorączka, mięśni, psychiczny }\end{array}$ & 285 & 6,3 \\
\hline smutek/Trauer 243, zmartwienie/Sorge 33 & 276 & 6,1 \\
\hline $\begin{array}{l}\text { brak/Fehlen von: zdrowia/Gesundheit } 74 \text {, sił } 26 \text {, pracy } 13 \text {, perspektyw } 13 \text {, } \\
\text { odporności 10, pomocy } 7 \text {, pieniędzy } 7 \text {, nadziei } 7 \text {, energii 5, akceptacji, apetytu } 2 \text {, } \\
\text { chęci } 2 \text {, chęci do życia } 2 \text {, chęci życia } 2 \text {, dóbr, dostępu do specjalistów, dyspozycji, } \\
\text { empatii, entuzjazmu, finansów, higieny } 2 \text {, jedzenia, kasy, kasy na leki, komfortu } 3 \text {, } \\
\text { kondycji, kontaktów 2, leczenia bo jest się za starym i nie chcą leczyć bo im się nie } \\
\text { opłaca, lekarstw } 3 \text {, lekarzy, motywacji, możliwości, możliwości kontaktu z innymi, } \\
\text { możliwości leczenia 2, możliwości porozumienia się z innymi, możliwości } \\
\text { poruszania się, możliwości pracy 2, na leczenie, odporności, opieki, opieki rodziny, } \\
\text { pewności siebie, poczucia radości, porządnej opieki zdrowotnej, pozytywnych } \\
\text { skutków leczenia, prawidłowego działania organizmu, refundacji leków, rozwoju, } \\
\text { ruchu, samodzielności 3, sił na wszystko, siły do pracy, spokoju, środków, środków } \\
\text { do życia 3, szacunku, szczęścia, wiary, wiedzy, wolności } 2 \text {, wpływu, wsparcia } 2 \text {, } \\
\text { współczucia, zdrówka, życia, życia z powodu chorób; braki } 2\end{array}$ & 239 & 5,3 \\
\hline $\begin{array}{l}\text { rodzaje chorób/Krankheitsarten: koronawirus } 35 \text {, rak } 32 \text {, wirus } 23 \text {, epidemia } 15 \text {, } \\
\text { grypa } 14 \text {, nowotwór } 9 \text {, bakterie } 8 \text {, aids } 3 \text {, wirus żoliborski - jarosław kaczyński }\end{array}$ & 140 & 3,1 \\
\hline śmierć/Tod & 140 & 3,1 \\
\hline $\begin{array}{l}\text { strach/Angst 114, strach o przyszłość } 2 \text {, strach o jutro, strach o pracę, strach } \\
\text { o zdrowie, strach o życie, strach przez utratą pracy }\end{array}$ & 121 & 2,7 \\
\hline $\begin{array}{l}\text { problemy/Probleme } 36 \text {, problem } 21 \text {, problemy zdrowotne } 8 \text {, problem z operacją, } \\
\text { problemy emocjonalne, problemy finansowe, problemy w rodzinie, problemy } \\
\text { w życiu }\end{array}$ & 70 & 1,6 \\
\hline bieda/Armut & 69 & 1,5 \\
\hline złość/Wut/Zorn & 46 & 1,0 \\
\hline
\end{tabular}

dern auch ein Land, die Politik, die Gesellschaft u.ä. (vgl. dazu die im Polnischen durchaus gängige Beschreibung negativ gesehener Zustände und Kontexte - auch und besonders im sozialen Bereich - als Pathologien/pathologisch). Das Wort hat 
somit eine recht vielfältige Semantik und ist entsprechend breit auf Kommunikationsthemen anwendbar. Vor dem Hintergrund der polnischen Datenlage insgesamt kann ihm daher durchaus kollektivsymbolischer Status zugesprochen werden.

Coronabezogene Aktualitäten (im Profil mit weiteren Krankheitsarten in einer Dimension zusammengefasst) nehmen einen nicht unbedeutenden Platz ein; insgesamt überwiegen im Gesamtprofil aber die beschriebenen, nicht aktualitätsbedingten Komponenten.

Tabelle 5c. Charakterisierung der Bedeutung von choroba - Bezüge auf Corona, Pandemie, aktuelle Situation etc.

\begin{tabular}{|l|l|r|r|}
\hline \multicolumn{1}{|c|}{ Kategorie } & \multicolumn{1}{|c|}{ Nennungen (N gesamt 4492) } & N & \% v. N \\
\hline $\begin{array}{l}\text { Bezüge auf Corona, } \\
\text { Virus, Pandemie }\end{array}$ & $\begin{array}{l}\text { koronawirus 35, korona } \\
\text { epidemia 15 } \\
\text { pandemia 7 } \\
\text { wirus 22, walka Z wirusem, wirusy } \\
\text { kwarantanna 5 }\end{array}$ & 91 & 2,03 \\
\hline $\begin{array}{l}\text { Bezüge auf den } \\
\text { aktuellen Moment }\end{array}$ & ostatnio też koronawirus i kwarantanna & 1 & 0,02 \\
\hline & \multicolumn{1}{|c|}{ Summe } & & 2,05 \\
\hline
\end{tabular}

Tabelle 5c zeigt nochmals deutlich, dass Bezüge auf die gegenwärtige Lage zwar durch Nennungen wie koronawirus, epidemia etc. erkennbar sind (manche davon auch lediglich potentieller Art); weitere direkte, wörtliche Bezugnahmen auf das „Jetzt“ (im Sinne von obecnie, teraz, dziś, aktualnie o.ä.) kommen jedoch nicht vor; auch die globalen Bezüge spielen hier keine Rolle.

\section{Fazit und Ausblick}

Die Ergebnisse verdeutlichen insgesamt, dass und wie der Einfluss von Aktualitäten auf Kollektivsymbole bzw. kollektivsymbolische Katalysatoren zumindest bei kurzem Andauern einer (wenn auch drastischen und so nie dagewesenen) Ausnahmesituation zwar feststellbar wird, aber, zumindest zunächst, in einem wenig bedeutsamen Rahmen verbleibt. Der Einfluss auf die Gesamtgestalt des jeweiligen semantischen Profils ist marginal.

Es steht zwar zu vermuten, dass der Anteil von auf Corona-Themen bezogenen Nennungen inzwischen - nach mittlerweile (zum Zeitpunkt des Verfassens des vorliegenden Textes) einjährigem Andauern einschneidender Maßnahmen und Veränderungen im gesellschaftlichen Leben - deutlich höher liegen dürfte. Mit einer Einengung und Reduzierung der hier präsentierten semantischen Profile auf 
dieses Thema ist jedoch dennoch nicht zu rechnen (angesichts der Gesamtdatenlage und der vorliegenden Erhebungen über einen Zeitraum 25 Jahren, die eine weitgehende Stabilität der Kollektivsymbole belegen). Analog zu dieser Stabilität, die metaphorisch gesprochen, nicht so leicht ins Wanken zu bringen ist, lässt sich die Strategie sehen, mit der die, teils dramatischen, coronabedingten Veränderungen, ungeachtet ihrer relativen Dauer, derzeit weiterhin zumeist als vorübergehend gekennzeichnet werden, nicht selten mit dem wörtlich ausgedrückten Wunsch nach (Rückkehr zur) Normalität. Diese explizite Positionierung der Dimension „Corona/Pandemie" außerhalb des Normalbereichs stellt an sich ein eigenes Untersuchungsthema dar; vor dem Hintergrund der Untersuchung von Kollektivsymbolen ergibt sich aus ihr die (hier vorläufig offen bleibende) Frage, inwieweit dieser Themenbereich an die Semantik von Gesundheit und Krankheit längerfristig angebunden (und also normalisiert) wird oder wieder verschwindet.

\section{Literaturverzeichnis}

BARTMIŃski Jerzy (Hrsg.), 2006, Język, wartości, polityka. Zmiany rozumienia nazw wartości w okresie transformacji ustrojowej w Polsce. Raport z badań empirycznych, Lublin.

BARtmiński Jerzy / Niebrzegowska-BARtmińska Stanisława / Nycz Ryszard (Hrsg.), 2004, Punkt widzenia w języku i kulturze, Lublin.

Fleischer Michael, 1995, Das System der polnischen Kollektivsymbolik, München.

Fleischer Michael, 1996, Das System der deutschen Kollektivsymbolik, Bochum.

FLeisCher Michael, 1997, Das System der russischen Kollektivsymbolik, München.

FLEISCHER Michael, 2003, System polskich symboli kolektywnych, Wrocław.

Fleischer Michael, 2006, Allgemeine Kommunikationstheorie, Oberhausen (Poln. - 2007: Ogólna teoria komunikacji, Wrocław).

Fleischer Michael / Siemes Annette, 2020, Świadomość i przynależność subkulturowa wśród młodzieży, in: Grech M./Lachowska K./Olender K./Siemes A. (Hrsg.), Badanie komunikacji / Projektowanie komunikacji, Vol. 3, Kraków, S. 9-64.

Fleischer Michael / Siemes Annette / Grech Michał, 2021, Die polnische und deutsche Kollektivsymbolik, Wiesbaden (Poln.: Stabilność polskiej i niemieckiej symboliki kolektywnej, Kraków) - in Druck.

HABRAJSKA Grażyna, 2012, Wybrane zagadnienia wprowadzające do nauki o komunikowaniu, Łódź.

LINK Jürgen, 1982, kollektivsymbolik und mediendiskurse, in: kultuRRevolution 1, S. 6-21.

LINK Jürgen, 1992, Normalismus: Konturen eines Konzepts, in: kultuRRevolution 27, S. 50-70.

LinK Jürgen, 1996, Versuch über den Normalismus. Wie Normalität produziert wird, Opladen.

LıNK Jürgen, 1999, Versuch eines „Konvertibilitäts“-Schemas zur Terminologie von Michael Fleischer, in: kultuRRevolution 38/39, S. 106-107.

Link Jürgen, 2013, Normale Krisen? Normalismus und die Krise der Gegenwart, Konstanz.

Link Jürgen / Loer Thomas / Neuendorff Hartmut (Hrsg.), 2003, 'Normalität' im Diskursnetz soziologischer Begriffe, Heidelberg.

Luhmann Niklas, 1990, Das Erkenntnisprogramm des Konstruktivismus und die unbekannt bleibende Realität, in: Luhmann N. (Hrsg.), Soziologische Aufklärung, 5. Konstruktivistische Perspektiven, Opladen, S. 31-58. 
Luhmann Niklas, 2004 [1991/92], Einführung in die Systemtheorie (Hrsg. D. Baecker, 2. Auflage), Darmstadt.

Peirce Charles S., 1931-58, Collected Papers, Vol. 1-6, Cambridge.

Peirce Charles S., 1983 (1903), Phänomen und Logik der Zeichen, Frankfurt am Main.

Pisarek Walery, 1992, Współczesne słowa sztandarowe w Polsce i ich publiczność, in: Zeszyty Prasoznawcze, R. XXXIII, Nr. 1-2 (129), S. 16-37.

Pisarek Walery, 2002, Polskie słowa sztandarowe i ich publiczność, Kraków.

Siemes Annette, 2013, Normalność w komunikacjach - jej negocjowanie i badanie. Na materiale komentarzy dotyczących architektury domów mieszkalnych, Łódź.

Siemes Annette, 2014, Voll normal. Die Untersuchung (der Aushandlung) von Normalitätsbereichen in der Kommunikation, in: Habrajska G. (Hrsg.), Symbolic Communication Strategies, Łódź, S. 38-64.

Siemes Annette, 2015, Normalność z perspektywy obserwatora - diagnoza, Łódź.

Siemes Annette, 2016, Miłość, dom, bezpieczeństwo. Mama, tata, dziecko. Raz - dwa - trzy - gotowe. Co?, in: Habrajska G./Ślósarska J. (Hrsg.), Strategie twórcze w działaniu, Łódź, S. 24-63.

SiEmES Annette, 2016a, Zdrowie jako motyw procedur normalizacyjnych w komunikacji - perspektywy badawcze na podstawie analizy egzemplifikacji, in: Grech M./Wszołek M./Siemes A. (Hrsg.), badanie i projektowanie komunikacji 5, Kraków, S. 99-117.

Wierzbicka Anna, 1997, Understanding Cultures through Their Keywords. English, Russian, Polish, German, and Japanese, Oxford.

\section{Gesundheit/zdrowie and Krankheit/choroba as communicationally semanticized language units and elements of the collective symbolism system in Germany and Poland}

The article deals with the words Gesundheit/zdrowie and Krankheit/choroba as communicationally semanticized language units, which have been analyzed (among other words) in the framework of a broader study concerning collective symbolism in Germany and Poland. In the context of the current situation that is characterized by the COVID-19 pandemic, both issues appear prominently in communications, so their detailed analysis seems to be particularly interesting. How the semantics of this words is shaped from the perspective of respondents who are asked to characterize their meaning? Moreover, the question comes up if and how such topicalities are reflected in the outcomes (collected, however, just at the beginning of the pandemic), particularly in the semantic profiles. It turns out that an effect manifests itself, but it is only added to existing semantic constellations that have been stable over decades, without modifying them basically.

Keywords: collective symbolism, communication research, Germany/Poland, Gesundheit/zdrowie, Krankheit/choroba, COVID-19 pandemic. 